\title{
CARTEL ENFORCEMENT WITH UNCERTAINTY ABOUT COSTS
}

\author{
By PETER C. CRAMTON AND ThOMAs R. PALFReY ${ }^{1}$
}

\begin{abstract}
What cartel agreements are possible when firms have private information about production costs? For private cost uncertainty we characterize the set of cartel agreements that can be supported, recognizing incentive and participation constraints. If defection results in either Cournot or Bertrand competition, the incentive problem in large cartels is severe enough to prevent the cartel from achieving the monopoly outcome. However, if the cartel agreement requires less than unanimous ratification by the member firms, then the incentive problem can be overcome in large cartels. With common cost uncertainty, perfect collusion is possible in large cartels, regardless of the ratification rule.
\end{abstract}

\section{INTRODUCTION}

Several firms are interested in forming a cartel in the hopes of improving profitability within the industry. Although the output of every firm is jointly observed, each firm has private information about its own production costs. For an industry with linear demand and linear production costs, we characterize the set of cartel agreements (called enforceable cartels) that can be supported as Bayesian Nash equilibria. We assume that side payments among firms are possible. Thus, a low-cost firm is able to bribe a high-cost firm into not producing. The bribery, however, is complicated by the incomplete information, since the firms may have an incentive to misrepresent their costs. A firm that is likely to have the lowest cost in the industry may be tempted to understate the size of the industry profits by overstating its costs, whereas a firm with high costs may prefer to understate its costs so as to overstate its willingness to produce.

This problem of explicit collusion in an industry with heterogeneous firms and private information was first considered formally by Roberts (1983). That paper concentrated on collusion without side payments, but briefly considered the side payment issue for the case in which there are two firms who have one of two possible marginal costs, high or low. For that case, he derives properties of the incentive compatibility constraints associated with a revelation game. He found that without side payments, if the firm types are sufficiently similar, then monopoly collusion cannot be achieved, but if side payments are allowed such collusion is possible with a dominant strategy mechanism essentially equivalent to the Vickrey (second-price) auction. In fact, it is not difficult to show that this result is true with any number of firms as long as there are only two types.

We present an alternative and more general model of the problem of optimal explicit cartel rules with side payments. There are two main differences between our approach and Roberts' (1983) analysis of the problem. The first is that we explicitly model the "threat" game, i.e., the opportunities for firms in the cartel to break the cartel if they find the rule unsatisfactory. ${ }^{2}$ In particular, we show how these threat games can be directly incorporated into the mathematical programming problem in the form of relatively simple individual rationality constraints, and analyze several plausible threat games. The second main difference is that we allow for a continuum of types. This turns out to be more than just a technical exercise, as Roberts' result for two types does not generalize to a continuum of types.

Explicit analysis of the threat game is important because the set of enforceable cartels depends in a crucial way on what happens if the firms cannot agree on an allocation mechanism. These outcomes in the face of disagreement determine each firm's individual rationality constraint. As an illustration, it may be that if one firm refuses to join the cartel, the cartel breaks down resulting in some form of incomplete information quantitysetting or price-setting competition between all the firms in the industry. If such competition results in Cournot or Bertrand outcomes, this would produce relatively weak individual rationality constraints, since the cartel would effectively be able to commit to relatively aggressive noncooperative behavior in the event one firm refuses to participate.

Alternatively, one might consider a stronger form of individual rationality in which if one firm refuses to join, the $n-1$ remaining firms continue as a cooperative cartel so that the industry looks more like a duopoly. Clearly, the less competitive is the behavior of the remaining $n-1$ firms, the stronger the individual rationality constraint becomes. Thus, if we instead assumed the $n-1$ remaining firms adopted the joint profit maximizing outcome in

\footnotetext{
${ }^{1}$ We would like to thank Richard Kihlstrom, Robert Porter, two anonymous referees and participants of seminars at University of Pennsylvania, Stanford University, Bell Communications Research, Princeton University, and University of California, Berkeley for valuable comments. We are grateful to Northwestern University for their hospitality and to the Sloan Foundation and the National Science Foundation for support.

${ }^{2}$ This is also the central difference between our work and a number of related studies with uncertainty about production costs, focusing primarily on regulatory issues. See, for example, Baron and Besanko (1984), Baron and Myerson (1982), Laffont and Tirole (1986), Loeb and Magat (1979), and Riordan and Sappington (1987).
} 
the face of a deviating firm, then the individual rationality constraint would be more severe and the set of enforceable cartels would be greatly reduced.

In either case, the individual rationality constraint is imposed at the interim stage, not the ex ante stage (as in Riordan and Sappington 1987). This is more in line with a view of cartel agreements as arising between existing heterogenous firms, than a view of cartel agreements being committed to prior to the specific realization of firms' costs in the industry. Nevertheless, as with most of the literature on mechanism design, we do not model the actual negotiation process through which the cartel members arrive at an incentive compatible, individually rational agreement. At the end of the paper we discuss how explicit incorporation of information leakage during an interim-stage process of choosing a mechanism might affect the results.

Consistent with this view of an agreement being made between a preexisting set of competing firms, is an assumption that there is no entry. This is important because the very nature of the cartel agreements studied here generates incentives for entry-in particular entry by firms who are very inefficient, and who will earn shares in the cartel profits by agreeing not to produce. We return to this issue in the last section.

With complete information it is easy to sustain the monopoly outcome via an enforceable cartel-simply have the lowest-cost firm produce the monopoly output and pay the other firms at least their Cournot or Bertrand profits. But with incomplete information, the monopoly outcome may not be enforceable due to the firms' incentives to misrepresent their true costs. Our main result is that when there are sufficiently many firms in the industry, the monopoly outcome is unobtainable, even with the weak individual rationality constraint given by our Cournot or Bertrand assumption. This result is in agreement with conventional wisdom that suggests as the number of firms grows, it becomes increasingly difficult to maintain the cartel.

In our model, the difficulty arises as a result of asymmetric information: relatively inefficient firms, since they are not easily identified, are able to free-ride on the profits created by the efficient firms. Simply put, with more firms, a greater amount of surplus is needed, since both producing and nonproducing firms have to be subsidized. We require that the aggregate subsidy cannot exceed the total (ex post) revenue generated by the cartel. With too many firms, not enough money is generated by the cartel to go around.

Although intuitive, the result does have some bite, since aside from the incomplete information about costs, our setting - symmetry, side payments, full information about quantities and other data, and an ability to limit entry and commit to an allocation mechanism - tends to favor efficient cartels. Hence, even when it is possible for the firms to establish binding agreements with side payments, the firms' incentives to misrepresent production costs precludes the formation of a cartel that attains the monopoly outcome.

This result, however, is sensitive to the form of uncertainty and the voting rule used to ratify the agreement. In particular, we show that if less than unanimous consent is needed to enforce the agreement, then the incentive problem becomes less severe as the number of firms grow. Similarly, with common cost uncertainty, the incentive problem is less severe in large cartels. By "common" we mean that all firms have identical but unknown cost functions and each firm has a private signal which is informative about these costs. For this case we do not characterize the optimal mechanism in general. Instead, we find a specific mechanism which achieves the monopoly outcome if there are enough firms. This result is established for a broad class of disagreement games, specifically, all games which satisfy a particular uniformity property. This contrasts sharply with the results for private cost uncertainty.

A third variation of the model that reverses our "no monopoly" result has recently been explored by Kihlstrom and Vives (1989). They consider a model with a continuum of firms and a finite number of types; whereas, we have a finite number of firms and a continuum of types. In their setting, they show that the monopoly outcome is enforceable. The informational problem is less severe in their model, since there is no uncertainty about the type of firm that should produce.

Finally, our result depends on the assumption that a firm cannot verify information about its competitors' costs. The informational problem would be reduced to the extent that firms can verify their private information about costs. In contrast, the literature on information sharing in oligopoly makes the opposite assumption that private information can be verified costlessly (see for example Clarke 1983; Gal-Or 1985, 1986; Shapiro 1986; and Vives 1984).

One might think that the occurrence of cartel agreements of the sort analyzed here would be rare, because of anti-trust laws that make explicit collusion and side payments illegal. However, there are many industries, even within a free-market economy such as in the United States, where explicit collusion and side payments is not only legal but actually encouraged by the costless enforcement of cartel agreements by the government. One example is the agricultural cartels (marketing orders) found in the market for hops, peppermint, oranges, and many other 
agricultural commodities. ${ }^{3}$ The hops market is especially interesting, since its history illustrates the difficulty firms may have in constructing an acceptable cartel agreement due to informational limitations. ${ }^{4}$ Another example (although not entirely sanctioned by government) is the collusion among oil companies in their bidding for oil leases. ${ }^{5}$ Here two or more informed firms owning neighboring tracts can reap substantial profits by colluding in their bids for nearby drainage tracts. Side payments between firms are easily camouflaged by including them in the unitization agreements that distribute profits from jointly owned oil pools. Finally, we might expect some degree of cartel formation involving side payments to exist in export industries with few firms, such as precious commodity production (diamonds and platinum), or in countries specializing in the export of a single agricultural commodity (coffee).

It should be clear from the above discussion that the problem we are studying is just a particular application of a much larger class of allocation problems which arise when there are collective decisions to be made in the presence of asymmetric information. Closely related problems would include efficient public good provision, and bilateral and multilateral bargaining. Hopefully some insights from the analysis here will carry over to those applications.

Before presenting our model, we want to emphasize that there are many alternative ways to pose the cartel problem when there is asymmetric information. A few possibilities have been mentioned above (side payments versus no side payments; different assumptions about what happens when the cartel falls apart-leading to different specifications of the individual rationality-constraints; the degree to which the cartel members are required to commit to the rules of the cartel; the form of the uncertainty; and the voting rule used to ratify an agreement). What we have tried to do is make assumptions which are conducive to the successful formation of efficient cartels. What we have shown is that, even within this favorable environment, if firms have private information about costs, a cartel cannot successfully enforce the monopoly outcome when there are many firms. We have, however, ignored dynamic aspects of cartel enforcement. A repeated game model of competition might well expand the set of enforceable cartels; however, if costs are serially correlated, then presumably some of the problems caused by private information in the static analysis would persist in the dynamic model. ${ }^{6}$ For example, if each firm's costs stay the same over time, then reputational considerations may well make it even more difficult to elicit cost information. On the other hand, if firms discount future profits very little, then some type of folk theorem might apply.

We begin by formulating the model and analyzing the direct revelation game (Section 2). Then in Section 3 we give necessary and sufficient conditions for a cartel to attain the monopoly outcome. Section 4 considers whether the monopoly outcome can be enforced when less than unanimous consent is needed for ratification of the cartel agreement. In Section 5, the example of uniform uncertainty is worked out to illustrate our more general results. Section 6 treats the common-cost case in which each firm has a private signal about a common industry production cost. We conclude with a discussion of some appealing extensions of our model. Proofs are provided in the Appendix.

\section{THE REVELATION GAME}

An industry consists of $n$ firms indexed by $i \in N=\{1, \ldots, n\}$. Each firm in the industry produces the quantity $q i$ of a homogeneous good and incurs linear production costs $c_{i} q_{i}$. The market price for the good depends on industry output $q=\left\{q_{1}, \ldots, q_{n}\right\}$ as given by the linear inverse demand $P(q)=a-\sum q_{i}{ }^{7}$ The output of each firm is jointly observable, but a firm's constant marginal $\operatorname{cost} c_{i}$ is known privately. Other firms know only that the private cost parameter of firm $i$ is drawn independently from a continuous distribution $F$. which has a positive

\footnotetext{
${ }^{3}$ See Hallagan (1985) for an analysis of the hops market, and Cave and Salant (1987) and Shepard (1986) for an analysis of the orange market.

${ }^{4}$ In explaining the rejection of a marketing order by the hops growers in 1965, Hallagan (1985, p. 49) argues, "The real problem inhibiting the formation of [cartel] agreements is the difficulty of finding low cost, nonmanipulatable mechanisms for extracting information on each grower's [competitive quantity] so that the initial allocation of base may be tied closer to [this competitive quantity], thus defusing opposition to the [cartel agreement]." As a postscript, the hops marketing order is no longer active as a result of antitrust action taken by the U.S. Department of Justice.

${ }^{5}$ See Hendricks and Porter (1988) for empirical evidence of collusion in bidding and McAfee and McMillan (1987) for a theoretical analysis of such collusion.

${ }^{6}$ For dynamic studies of collusive behavior, see Abreu (1986), Abreu, Pearce, and Stacchetti (1986), Fudenberg and Maskin (1986), Green and Porter (1984), and Porter (1983). Madrigal (1988) has explored one model of information revelation in a dynamic context with uncertainty about a common demand component which is repeatedly and independently drawn each period.

${ }^{7}$ None of the characterization results in this section depend on our assumption of a linear demand curve or the assumption of linear costs. What is important is that the private information enter linearly in the form $C_{i}\left(q_{i}\right)=c_{i} H\left(q_{i}\right)$, where $H(\cdot)$ is some continuous increasing function. Both assumptions, however, do play important simplifying roles in later sections.
} 
density $\mathrm{f}$ on $[\underline{c}, \bar{c}]$ with $\bar{c} \leq a$. Industry information, such as the demand schedule, the form of the cost function, and the distribution $F$, is common knowledge.

In deriving the set of enforceable cartels, we consider the class of direct revelation games in which firms simultaneously report their marginal costs $c=\left\{c_{1}, \ldots, c_{n}\right\}$, resulting in an allocation $q(c)=\left\{q_{1}(c), \ldots, q_{n}(c)\right\}$ and $r(c)=\left\{r_{1}(c), \ldots, r_{n}(c)\right\}$, where $q_{i} \geq 0$ is the output of firm $i$ and $r_{i}$ is firm $i$ 's share of the industry revenues for producing $q_{i}{ }^{8}$ The pair of outcome rules $\langle q, r\rangle$, which determine an allocation as a function of the firms' reports, is called a cartel. A feasible cartel satisfies the ex post budget balance constraint that the sum of the revenue shares equals the total industry revenue:

$$
\sum_{i=1}^{n} r_{i}(c)=\rho(c) \equiv\left[a-\sum_{i=1}^{n} q_{i}(c)\right] \sum_{i=1}^{n} q_{i}(c) \text { for all } c \in[\underline{c}, \bar{c}]^{n} .
$$

A firm seeks to maximize expected profit. Ex post a firm with cost $c_{i}$, producing the quantity $q_{i}$, and receiving the revenue $r_{i}$ has a profit of $r_{i}-c_{i} q_{i}$. Let $-i=M i$ and let $E_{-i}\{\cdot\}$ be the expectation operator with respect to $c_{-i}$. Then we can define the expected production and revenue for firm $i$ when it announces $c_{i}$ by

$$
Q_{i}\left(c_{i}\right)=E_{-i}\left\{q_{i}(c)\right\} \quad R_{i}\left(c_{i}\right)=E_{-i}\left\{r_{i}(c)\right\}
$$

so the firm's expected profit is

$$
\pi_{i}\left(c_{i}\right)=R_{i}\left(c_{i}\right)-c_{i} Q_{i}\left(c_{i}\right)
$$

Incentive Compatibility. A cartel $\langle q, r\rangle$ is incentive compatible if all types of all firms want to report their private information truthfully:

$$
\pi_{i}\left(c_{i}\right)=\geq R_{i}(v)-c_{i} Q_{i}(v) \quad \text { for all } \quad i \in N, \quad \text { and } \quad c_{i}, v \in[\underline{c}, \bar{c}]
$$

By the revelation principle, we lose no generality by restricting attention to incentive compatible cartels.

The assumptions of independence and risk neutrality allow us to give a convenient representation of incentive compatibility. In particular, for any incentive compatible cartel, there is a precise relationship between the expected revenue $R_{i}$ and the expected production $Q_{i}$ : once $q$ is specified both $\pi_{i}$ and $R_{i}$ are determined up to a constant.

LEMMA 1. The cartel $\langle q, r\rangle$ is incentive compatible if and only if for every $i \in N, Q_{i}$ is decreasing and for all $c^{\prime}, c_{i} \in[\underline{c}, \bar{c}]$

$$
R_{i}\left(c^{\prime}\right)-R_{i}\left(c_{i}\right)=\int_{c_{i}}^{c^{\prime}} v d Q_{i}(v)
$$

Moreover, if $\cdot q$, rÒis incentive compatible, then $\mathrm{p}_{i}$ is convex and decreasing with derivative $d \mathrm{p}_{i} / d c_{i}=-Q_{i}$ almost everywhere and for all $c^{\prime}, c_{i} \in[\underline{c}, \bar{c}]$

$$
\pi_{i}\left(c^{\prime}\right)-\pi_{i}\left(c_{i}\right)=-\int_{c_{i}}^{c^{\prime}} Q_{i}(v) d v
$$

Individual Rationality. In order to define the set of enforceable cartels, it is necessary to specify exactly what happens if one firm refuses to join (or defects from) the cartel. In this section, we assume that a single defection from the proposed cartel by one of the firms leads to a complete break down of the cartel and so the industry produces as an $n$-firm oligopoly with output determined by the symmetric competitive threat $\theta$. Let $\pi^{\theta}\left(c_{i}\right)$ be the expected firm profit under threat $\theta$ if one or more firms refuse to participate in the cartel. Similarly, define $Q^{\theta}\left(c_{i}\right)$ and $R^{\theta}\left(c_{i}\right)$ to be the expected quantity and revenue of firm $c_{i}$ under threat $\theta$ if the cartel breaks down. The

\footnotetext{
${ }^{8}$ Our analysis of the direct revelation game draws heavily upon the prior work of Baron and Myerson (1982), Cramton, Gibbons and Klemperer (1987), Myerson (1981), and Myerson and Satterthwaite (1983).
} 
functions $\pi^{\theta}$, $Q^{\theta}$, and $R^{\theta}$ are determined in the next section for both Cournot $(\theta=C)$ and $\operatorname{Bertrand}(\theta=B)$ competition. These functions do not depend on i due to the symmetry of the model.

The cartel $\langle q, r\rangle$ is said to be individually rational with respect to the threat $\theta$ if all firms are better-off joining the cartel than defecting:

$$
\pi_{i}\left(c_{i}\right) \geq \pi^{\theta}\left(c_{i}\right) \text { for all } i \in N \text { and } \quad c_{i} \in[\underline{c}, \bar{c}]
$$

A feasible cartel that is incentive compatible and individually rational is called an enforceable cartel, since the allocation implied by an enforceable cartel is the outcome of a Bayesian Nash equilibrium. To verify if a cartel satisfies individual rationality, it is only necessary to check whether the worst-off type of firm, i.e., the firm $c_{i}$ for whom $\pi_{i}\left(c_{i}\right)-\pi^{\theta}\left(c_{i}\right)$ is minimized, prefers the cartel payoff $\pi_{i}\left(c_{i}\right)$ to the competitive payoff $\pi^{\theta}\left(c_{i}\right)$. The following lemma identifies the possible candidates for the worst-off type.

LEMMA 2. An incentive compatible cartel $\langle q, r\rangle$ is individually rational if and only if for all $i \in N$ and $\hat{c}_{i} \in \hat{C}_{i}=\{\underline{c}, \bar{c}\} \cup\left\{c_{i} \mid Q_{i}\left(c_{i}\right)=Q^{\theta}\left(c_{i}\right)\right\}$

$$
\pi_{i}\left(\hat{c}_{i}\right) \geq \pi^{\theta}\left(\hat{c}_{i}\right)
$$

Lemma 2 states that the worst-off type of firm is either at an extreme point ( $\underline{c}$ or $\bar{c})$ or at an interior point $c_{i}$ such that the firm's expected production under the cartel agreement is equal to the production without the cartel. Notice that a firm's net payoff $U_{i}^{\theta}(\cdot)=\pi_{i}(\cdot)-\pi^{\theta}(\cdot)$ is increasing whenever expected production with the cartel is less than production without the cartel. The possibility that the individual rationality constraint may bind at an interior cost is an unusual feature of the problem we are studying. More commonly, individual rationality constraints enter as inequality conditions on boundary types. In contrast, when this constraint binds on an interior type, we are able to characterize it by a first order condition stating that the binding type's interim expected output in the mechanism equals its interim expected output in the threat game.

We now provide a general characterization of enforceable symmetric cartels. Specifically, necessary and sufficient conditions for a production rule $q$ to be part of an enforceable cartel are given. The case of asymmetric cartels is treated in Lemma 3 in the Appendix. However, because of the symmetry of our model, nothing is gained by permitting asymmetric cartels; hence, in what follows we will restrict attention to symmetric cartels and frequently drop the subscript $i$. A cartel $\langle q, r\rangle$ is symmetric if both $q$ and $r$ are symmetric, so that $Q_{i}(\cdot)=$ $Q_{j}(\cdot) \equiv Q(\cdot)$ and $R_{i}(\cdot)=R_{j}(\cdot) \equiv R(\cdot)$ for all $i, j \in N$.

THEOREM 1. For any symmetric production rule $q \geq 0$, there exists a symmetric revenue rule $r$ such that the cartel $\langle q, r\rangle$ is enforceable if and only if $Q(\cdot)$ is decreasing and for all $\hat{c} \in\{\underline{c}, \bar{c}\} \cup\left\{v \mid Q(v)=Q^{\theta}(\theta)\right\}$

$$
\pi(\bar{c})+\int Q(v) d v \geq \pi^{\theta}(\hat{c})
$$

where

$$
\pi(\bar{c})=\frac{1}{n} E[\rho(c)]-\bar{c} Q(\bar{c})+\int v F(v) d Q(v)
$$

An implication of Theorem 1 is that once $q$ is specified, interim profit $\pi(c)$ and revenue $R(c)$ are uniquely determined by the incentive-compatibility condition in Lemma 1, budget balance, and symmetry. Without symmetry, arbitrary lump sum transfers can be made between firms, but this does not make it easier to satisfy individual rationality, since we assume that the threat game is symmetric.

\section{EX POST EFFICIENCY}


A cartel $\langle q, r\rangle$ is ex post efficient if for each vector of costs $c$ the outcome of the agreement $\{q(c), r(c)\}$ is Pareto undominated by any alternative allocation, ignoring incentive constraints. Thus, ex post efficiency, due to our assumption of constant returns to scale, requires that the lowest-cost firm produces the monopoly output and the other firms produce nothing. In this section, we answer the question of whether this monopoly outcome can be attained by an enforceable cartel. We begin by determining the monopoly outcome.

The expected quantity $Q^{M}(c)$ that a firm with cost $c$ will produce in a joint monopoly is simply the monopoly output $(a-c) / 2$ times the probability that the firm with cost $c$ has the lowest cost, $G(c)=[1-F(c)]^{n-1}$. Hence, $Q^{M}(c)=1 / 2(a-c) G(c)$. Once $q$ is fixed to be the joint monopoly outcome, the interim profits $\pi^{M}$ and revenue $R^{M}$ are fixed by incentive compatibility, budget balance, and symmetry as in Theorem 1 . The next lemma derives the interim profits of an ex post efficient cartel.

LEMMA 4. In a symmetric, ex post efficient, incentive compatible cartel, the expected profit (and revenue) to the highest-cost firm is an equal share of the expected industry profit if the second most profitable firm were to produce its monopoly output; namely,

$$
\pi^{M}(\bar{c})=R^{M}(\bar{c})=\int_{\underline{c}}^{\bar{c}} \frac{1}{4}(a-v)^{2}(n-1) f(v) F(v)[1-F(v)]^{n-2} d v>0,
$$

implying profits for a firm with cost $c$ of

$$
\pi^{M}(c)=\pi^{M}(\bar{c})+\int_{\underline{c}}^{\bar{c}} Q^{M}(v) d v .
$$

An immediate implication of Lemma 4 is that if the threat outcome is exclusion from the industry (zero profits), then the monopoly outcome is enforceable since it results in positive profits for all because $\pi^{M}(\bar{c})>0$.

Lemma 4 suggests why it is difficult to enforce the monopoly outcome: the highest-cost firm must be paid a substantial amount of money to report its type truthfully, even if it would not produce without the cartel. As the number of firms grows, the amount paid to the highest-cost firm converges to an equal share of the industry profits when the lowest-cost firm produces the monopoly output. But since all lower-cost firms must be paid strictly more, there is not enough money to go around and still satisfy budget balance.

Intuition for why the highest-cost firm must receive an equal share of the monopoly profits when the second lowest-cost firm produces the monopoly output can be gleaned from the auction literature. ${ }^{9}$ We can imagine that the firms are bidding for the right to be the monopolist in the industry. If firm $i$ has $\operatorname{cost} c_{i}$, the value of the right is $v_{i}=\left(a-c_{i}\right)^{2} / 4$. Hence, we can interpret our model as a private value model of exchange. In an efficient equilibrium of this private value auction, the total expected surplus is $E\left[v_{(1)}\right]$ and the expected informational rent to the winning bidder is $E\left[v_{(1)}-v_{(2)}\right]$, where $v_{(k)}$ is the kth order statistic of the $n$ values $v_{i}$. The equilibrium outcome is for the winning bidder to receive the information rent $E\left[v_{(1)}-v_{(2)}\right]$ and then for the remaining surplus $E\left[v_{(2)}\right]$ to be split equally among the $n$ firms. Indeed, the monopoly mechanism can be incentive-compatibility implemented as a first-price, sealed-bid auction in this way: each firm bids $b\left(v_{i}\right)$ for the right to produce as a monopolist, the highest bidder wins the right and divides its bid equally among the others.

It now remains to check individual rationality. This requires a comparison, for each $c$, of the interim profit, $\pi^{M}(c)$, from the ex post efficient cartel with the interim profit in the threat game. If $\pi^{M}(c)$ is always greater than or equal to the interim profits of the threat game for every $c \in[\underline{c}, \bar{c}]$, then the joint monopoly cartel is enforceable relative to that threat game.

We consider and compare two alternative threat outcomes (in addition to exclusion from the industry): Cournot competition and Bertrand competition. The production and profit from each threat are given in the next two lemmas.

LEMMA 5. Under Cournot competition the quantity $Q^{C}(c)$ and profit $\pi^{C}(c)$ of a firm with cost c are given by

$$
Q^{C}(c)= \begin{cases}0 & \text { if } c \geq \tilde{c} \\ \frac{1}{2}(\tilde{c}-c)^{2} & \text { if } c<\tilde{c}\end{cases}
$$

\footnotetext{
${ }^{9}$ See McAfee and McMillan (1987), who derive a similar result in their analysis of collusion in a private-value auction.
} 


$$
\pi^{C}(c)= \begin{cases}0 & \text { if } c \geq \tilde{c} \\ \frac{1}{4}(\widetilde{c}-c)^{2} & \text { if } c<\widetilde{c}\end{cases}
$$

where $\tilde{c}=\bar{c}$ if $2(a-\bar{c}) \geq(n-1)\left[\bar{c}-E_{i}(c)\right]$ and otherwise $\tilde{c}$ is defined implicitly (and uniquely) by the equation

$$
2(a-\tilde{c})=(n-1) \int_{\underline{c}}^{\bar{c}} F(v) d v .
$$

With Bertrand competition, since output is homogeneous, only the lowest cost firm will produce, since it will be able to undercut all other firms. We imagine the pricing game working in approximately the following way. Each firm posts a price. After seeing all other firms' prices, each firm can post a (lower) price if it wishes. The procedure stops when no firm lowers its price. The lowest-priced firm satisfies demand at its final posted price. This game is strategically similar to an English auction. Each firm will initially post its monopoly price, $(a+c) / 2$, and from then on meet the lowest competing price until that price falls below $c$.

LEMMA 6. Under Bertrand competition the quantity $Q^{B}(c)$ and profit $\pi^{B}(c)$ are given by

$$
\begin{gathered}
Q^{B}(c)=(a-c) G(c)-\int_{c}^{1 / 2(a+c)} G(v) d v \\
\pi^{B}(c)=\int_{c}^{1 / 2(a+c)}(a+c-2 v) G(v) d v
\end{gathered}
$$

where $G(v)=[1-F(v)]^{n-1}$.

The next two theorems give a necessary and sufficient condition for the monopoly outcome to be enforceable with either a Cournot or Bertrand threat. Simply put, the necessary and sufficient condition is that individual rationality must be satisfied for the worst-off type. With Cournot competition, this worst-off type occurs at an interior point $\hat{c}$ such that firm $\hat{c}$ 's production is the same with or without the cartel. With Bertrand competition, the worst-off type is $\underline{c}$, since the monopoly output is less than the Bertrand output for all types of firms, and hence a firm's net profit $U^{\bar{C}}(\cdot)$ is increasing.

THEOREM 2. Under a threat of Cournot competition, the monopoly outcome can be attained by an enforceable cartel if and only if for all $\hat{c}$ such that $Q^{M}(\hat{c})=Q^{C}(\hat{c})$ we have

$$
\pi^{M}(\hat{c}) \geq \pi^{C}(\hat{c})
$$

THEOREM 3. Under a threat of Bertrand competition, the monopoly outcome can be attained by an enforceable cartel if and only if

$$
\pi^{M}(\underline{c}) \geq \pi^{B}(\underline{c})
$$

In determining what happens when the number of firms increases, it perhaps makes more sense to expand demand as $n$ grows, so that if the number of firms doubles then industry demand doubles as well. In this case, the inverse demand is given by $P(q)=a-(1 / n) \sum q_{i}$. It is easy to show that the effect of expanding demand as $n$ increases is to increase profit, revenue, and production by a factor of $n$, due to the linearity of costs. Moreover, the values $\hat{c}$ and $\tilde{c}$ are the same as when demand is held constant. Thus, the set of enforceable cartels remains the same whether demand is held constant or expanded as $n$ increases. That ex post efficiency is unattainable as $n$ grows is a consequence of the heightened competition among firms, rather than dividing a pie of constant size into smaller pieces.

It has proven difficult to show in general that ex post efficiency is not obtainable with sufficiently many firms. In order to derive the result for Cournot competition we need to show that $\hat{c}$ converges to $\underline{c}$ much faster than $\tilde{c}$. This is difficult, since there is no explicit solution for $\tilde{c}$ and $\hat{c}$ in general. We can, however, demonstrate the result for both Cournot and Bertrand competition when costs are uniformly distributed. In addition, the next 
theorem provides a general result for the Bertrand threat, assuming the distribution $F$ satisfies the condition below.

DEFINITION. The distribution $F$ is unconcentrated at $\underline{c}$ if there exists $c^{\circ}>\underline{c}$ such that for all $c \in\left(\underline{c}, c^{\circ}\right], F(c)<2(c-\underline{c}) /(a-\underline{c})$.

THEOREM 4. If $F$ is unconcentrated at $\underline{c}$, then for sufficiently large $n$, the monopoly outcome is not enforceable by the Bertrand threat.

\section{NONUNANIMOUS VOTING RULES}

The standard approach to incorporating individual rationality into the mechanism design problem, and indeed the approach we have taken in the previous sections, requires every type of all firms to receive an interim profit from the mechanism which is no less than their profit from the threat game. This is analogous to a voting rule in which the mechanism is required to pass unanimous interim consent, and if ratification fails, revert to some prespecified status quo competition - the threat game. In other words, nonparticipation by any member of the group has the ability to unilaterally upset the proposed cartel agreement.

A weaker form of individual rationality emerges if the ratification procedure is not required to be unanimous, as is the case in some government sanctioned cartels such as marketing orders, where two-thirds majority rule is required to enforce a cartel agreement. In this section we examine the implications for mechanism design under an $\alpha$-majority rule for ratification: only a proportion $\alpha \in(0,1]$ of the firms are needed to ratify the mechanisms at the interim stage. If at least that many firms ratify the mechanism, then each firm must follow the cartel agreement or exit the industry. The standard individual-rationality condition is of course a special case of this $(\alpha$ $=1)$.

What we demonstrate below is that it is in fact that the unanimity requirement that constrains the cartel from achieving the joint monopoly outcome when there are many firms. Specifically, we prove that for any "reasonable" threat game and for any $\alpha<1$, the joint monopoly outcome can be achieved in the limit as the number of firms becomes large. This result may appear surprising since it seems to contradict conventional wisdom that collusion becomes more difficult when a cartel is larger. Indeed, strong confirmation of that belief seemed to follow from the standard analysis of individual rationality constraints provided in the previous section.

It is then important to identify the source of this conflict. First, as the number of firms gets larger, there is essentially no uncertainty about which type of firm should do the producing. Moreover, all firms except those with costs close to $\underline{c}$ are treated essentially equally, since they are all (nearly) equally inefficient firms, in the sense that they are asked to produce with probability close to 0 - each receives approximately $1 / n$ times the expected monopoly profits. But a firm with $\operatorname{cost} \underline{\underline{c}}$ is treated differently, since it is surely asked to produce. In the limit, this asymmetry induces a discontinuity in the individual rationality constraint, $\pi^{M}(c) \geq \pi^{\theta}(c)$, which is violated for a $\underline{c}$ firm, but (in the limit) is not binding for firms with costs arbitrarily close to $\underline{c} .{ }^{10}$ This intuition is formalized below. Rather than specifying the exact structure of a threat game, we represent any threat game by the interim expected profit functions induced by symmetric Bayesian equilibrium behavior of the firms under the incentives generated by the threat game.

Let $\pi_{n}^{\theta}(\cdot)$ denote the interim expected profits at a symmetric equilibrium of some $n$-firm threat game, $\theta_{n}$. Since we are interested in enforcing cartels with many firms, we consider sequences of threat games. Such a sequence is denoted $\left(\theta_{n}\right)_{n=2}^{\infty}$. Fixing $\theta$, we define the following:

DEFINITION. A threat sequence, $\theta$, is uniformly nonmonopolistic if there exists $\varepsilon>0$ and $N>1$, such that for all $n>N$. and for all $v>\underline{c}, n\left[\pi_{n}^{\theta}(v)\right]+\varepsilon<[(a-\underline{c}) / 2]^{2}$.

In other words, a uniformly nonmonopolistic threat sequence has the property that, except possibly for the lowest cost firm, the profit of every type is uniformly bounded away from an equal share of the highest possible (full information) cartel profits, which arise if the monopolistic production costs are $\underline{c}$. This is a very weak condition, and is satisfied by virtually any market organization except joint monopoly itself. For example, this condition is satisfied by the threat sequence defined by $n$-firm Cournot quantity for all $n$.

\footnotetext{
${ }^{10}$ Our limiting result can be criticized on the grounds that individual rationality is violated for precisely the firm that is doing all the production. One might imagine that such a firm should have a greater voice in the ratification process.
} 
Given a feasible cartel, $\langle q, r\rangle$, and a threat sequence $\theta$, denote by $\mathrm{V}_{n}\left(\langle q, r\rangle, \theta_{n}\right)$, the Veto set, which is the subset of $[\underline{c}, \bar{c}]$ for which the interim expected profits from participation in the $n$-firm cartel is less than the interim expected profits under $\theta_{n}$.

This set of firm types would not ratify the cartel mechanism $\langle q, r\rangle$ at the interim stage.

DEFINITION. A mechanism $\langle q, r\rangle$ is $\alpha$-individually rational under threat $\theta$ if there exists $\delta>0$ and $N$ such that for all $n>N$,

$$
\int_{V_{n}\left(\langle q, r\rangle, \theta_{n}\right)} d F(c)<(1-\alpha)-\delta
$$

LEMMA 7. If $\langle q, r\rangle$ is $\alpha$-individually rational under $\theta$, then the probability that at least n $\alpha$ of the firms have costs lying outside $V_{n}\left(\langle q, r\rangle, \theta_{n}\right)$ approaches 1 as $n \rightarrow \infty$; that is, the probability of ratification by $\alpha$-majority rule goes to 1 as $n \rightarrow \infty$.

THEOREM 5. If $\theta$ is uniformly nonmonopolistic then the ex post efficient cartel rule is $\alpha$-individually rational under threat $\theta$ for all $\alpha<1$.

An assumption implicit in the above analysis is that the threat payoffs are unaffected by the voting process itself. One can make an argument that the payoffs of the threat game are not appropriately modelled as interim expected profits since firms will have an opportunity to make inferences about the other firms as a result of the voting outcome. This information may then be used to update their prior beliefs about the other firms. These new beliefs produce what could be called post-interim threats, which in general could depend upon the entire vector of costs. Nonetheless, at the voting stage, the firms do not yet know the voting outcome, so one may simply interpret our interim threat $\theta$ as the (interim) expectation of the post-interim threats. We return to this issue in the concluding section.

\section{AN EXAMPLE WITH UNIFORM COSTS}

Suppose that $a=1$ and the firms' costs are uniformly distributed on [0,1]. From Lemma 4, the joint monopoly profit $\pi^{M}(c)$ is given by

$$
\pi^{M}(c)=\frac{n-1}{4(n+1)(n+2)}+\frac{(1-c)^{n+1}}{2(n+1)},
$$

since

and

$$
\pi^{M}(1)=\int_{0}^{1} \frac{1}{4}(n-1) v(1-v)^{n} d v=\frac{n-1}{4(n+1)(n+2)},
$$

$$
\int_{c}^{\bar{c}} Q^{M}(v) d v=\int_{c}^{1} \frac{1}{2}(1-v)^{n} d v=\frac{(1-c)^{n+1}}{2(n+1)} .
$$


TABLE 1

NUMERICAL CALCULATIONS WITH $a=1$ AND $F(v)=v$

\begin{tabular}{|c|c|c|c|c|c|c|c|c|}
\hline$n$ & 2 & 4 & 8 & 16 & 32 & 64 & 128 & $\infty$ \\
\hline$\hat{c}$ & .21995 & .15371 & .10290 & .06629 & .04132 & .02505 & .01484 & 0 \\
\hline$\tilde{c}$ & .82843 & .66667 & .52241 & .40000 & .30044 & .22222 & .16242 & 0 \\
\hline Outcome & \multicolumn{8}{|c|}{ Ex Ante Industry Quantity } \\
\hline Monopoly & .33333 & .40000 & .44444 & .47059 & .48485 & .49231 & .49612 & .5 \\
\hline Cournot & .34315 & .44444 & .54582 & .64000 & .72212 & .79012 & .84417 & 1 \\
\hline Bertrand & .66536 & .79844 & .88715 & .93934 & .96780 & .98269 & .99031 & 1 \\
\hline Outcome & \multicolumn{8}{|c|}{ Ex Ante Industry Profit } \\
\hline Monopoly & .12500 & .16667 & .20000 & .22222 & .23529 & .24242 & .24615 & .25 \\
\hline Cournot & .09476 & .09877 & .09505 & .08533 & .07232 & .05853 & .04570 & 0 \\
\hline Bertrand & .16634 & .13307 & .08872 & .05219 & .02846 & .01489 & .00762 & 0 \\
\hline Threat & \multicolumn{8}{|c|}{$n$ times Net Payoff of Monopoly Cartel for Worst-Off Type } \\
\hline Cournot & .01476 & .01052 & -.02916 & -.10273 & -.19566 & -.29242 & -.38252 & -.75 \\
\hline Bertrand & -.0417 & -.1125 & -.1782 & -.2157 & -.2335 & -.2420 & -.2460 & -.25 \\
\hline Threat & \multicolumn{8}{|c|}{ Proportion of Firms Who Prefer Monopoly Cartel to Threat } \\
\hline Cournot & 1.00000 & 1.00000 & .85005 & .83898 & .86744 & .89909 & .92461 & 1 \\
\hline Bertrand & .79370 & .86006 & .91867 & .95730 & .97839 & .98917 & .99458 & 1 \\
\hline
\end{tabular}

To determine the Cournot outcome we must first calculate $\tilde{c}$ and $\hat{c}$. Substituting $F(v)=v,(\tilde{C})$ can be written as

$$
2(1-\tilde{c})=(n-1) \int_{0}^{\tilde{c}} v d v,
$$

which implies that $\tilde{c}=2(\sqrt{n}+1)$. In addition, for an ex post efficient cartel, $Q^{M}(v)=\frac{1}{2}(1-v)^{n}$, so that $\hat{c}$ is found by finding the first positive root of the equation $(1-\hat{c})^{n}=\tilde{c}-\hat{c}$. By substituting these values into $(M C)$, we get that the monopoly outcome is enforceable (unanimously) with a Cournot threat if and only if

$$
\frac{n-1}{4(n+1)(n+2)}+\frac{(1-\hat{c})^{n+1}}{2(n+1)} \geq \frac{1}{4}(\tilde{c}-\hat{c})^{2},
$$

where $\tilde{c}=2(\sqrt{n}+1)$ and $\hat{c}$ is the first positive root of $(1-\hat{c})^{n}=\tilde{c}-\hat{c}$.

For Bertrand competition, the interim production is

$$
Q^{B}(c)=(1-c)^{n}-\int_{c}^{\frac{1}{2}(1+c)}(1-v)^{n-1} d v=\beta(1-c)^{n}
$$

where $\beta=1-(1 / n)\left(1-2^{-n}\right)$. A similar calculation yields $\pi^{B}(\underline{c})=\beta /(n+1)$. Hence, by substituting into $(M B)$, we get that the monopoly outcome can be unanimously enforced with a Bertrand threat if and only if

$$
\frac{3}{4(n+2)} \geq \frac{\beta}{n+1} .
$$

Table 1 presents numerical calculations for several $n$. Of particular interest are the last four rows in the table, which indicate the net benefit to the worst-off type from the monopoly cartel and the proportion of firms that prefer the monopoly cartel to the threat game. We can see that if unanimous consent is needed, then with a Bertrand threat the monopoly outcome is never enforceable, whereas with a Cournot threat the monopoly outcome is enforceable if and only if $n \leq 5$. In either case, however, the vast majority of firms prefer the monopoly outcome to the threat game, so that even with $\alpha$ fairly close to 1 , the monopoly outcome is enforceable. Observe that as $n$ increases the proportion of firms that prefer the monopoly outcome converges to 1, illustrating Theorem 5. In contrast to this, note from the table that the worst-off type is increasingly worse off as the number of firms becomes large. This suggests that the "optimal" enforceable cartel probably does not approximate the ex post efficient (joint monopoly) solution when $n$ is large. We have been unable to prove this conjecture. The example with costs uniform on $[\underline{c}, 1]$ where $\underline{c} \in[0,1)$ is easy to analyze as well, but this change has no effect, other than a simple resealing, due to the fact that linearity is preserved. 


\section{ENFORCEABLE CARTELS WITH COMMON VALUE UNCERTAINTY}

Sections 2 through 5 presented results for a private value model in which firm types (costs) are independent. This section presents a related analysis for the case in which firms have a common (but uncertain) cost, $c$, and each receives a signal, $s_{i}$, about the cost. While the basic approach is quite similar, the problem facing the cartel is much different, and much easier in at least one important respect. In particular, to achieve the joint monopoly outcome it is no longer necessary for the cartel to identify the most efficient firm, since all firms are equally efficient. The only uncertainty is how much to produce in aggregate, so the cartel has an extra degree of freedom: how to share production. Since total industry profits are independent of the individual allocation of production levels, it may be possible to generate effective side payments simply by altering the assigned production allocations.

As before, we may think of a cartel as a pair of functions $\langle q(\cdot), r(\cdot)\rangle$ that maps each vector of firm types into a vector of revenue shares and output assignments, respectively. It is feasible if the sum of the revenue shares never exceed the total cartel revenues. However, because of the information structure, a firm's expected profit is not quite so easy to represent. Denote

$$
\begin{aligned}
& Q_{i}\left(c, s_{i}\right)=E_{-i}\left\{q_{i}\left(s_{-i}, s_{i}\right) \mid c\right\} \\
& R_{i}\left(c, s_{i}\right)=E_{-i}\left\{r_{i}\left(s_{-i}, s_{i}\right) \mid c\right\} .
\end{aligned}
$$

Then, if the "true" cost equals $c$, and a firm receives signal $s_{i}$, we have

$$
U_{i}\left(c, s_{i}\right)=R_{i}\left(c, s_{i}\right)-c Q_{i}\left(c, s_{i}\right)
$$

Expecting over $c$, after conditioning on $s_{i}$ gives

$$
U_{i}\left(s_{i}\right)=R_{i}\left(s_{i}\right)-E_{c}\left\{c Q_{i}\left(c, s_{i}\right) \mid s_{i}\right\}
$$

where $U_{i}\left(s_{i}\right)=E_{c}\left\{U_{i}\left(c, s_{i}\right) \mid s_{i}\right\}$ and $R_{i}\left(s_{i}\right)=E_{c}\left\{R_{i}\left(c, s_{i}\right) \mid s_{i}\right\}$. At this point we encounter some difficulty since (IC') apparently does not produce a single "envelope" characterization of incentive compatibility, like the one obtained for the private values model in Lemma 1. A sufficient (but not necessary) condition for incentive compatibility can be obtained as in Lemma 1 by applying the usual techniques to (IC), for each realization of $c$, but this is not particularly useful.

Thus the revelation principle approach appears to have limited usefulness in this context, at least for the purpose of characterizing mechanisms. ${ }^{11}$ Fortunately, this problem contains sufficient structure so that we can still establish several interesting results relating to the question of enforcing the joint monopoly solution, without deriving a condition analogous to $(E)$. In particular, we provide a set of assumptions about the threat game which is sufficient to guarantee the ability of large cartels to successfully attain the monopoly solution. This contrasts sharply with the results for private costs.

To establish this result, we examine a simple cartel rule which is incentive compatible. We then specify conditions on the threat game such that the cartel rule will also be individually rational. The mechanism is the simplest imaginable one, which we call equal-share information pooling. Each firm is asked to report $s_{i}$. This determines an optimal (monopoly) aggregate cartel production level $q^{M}\left(s_{1}, \ldots, s_{n}\right)$. Each firm is then required to produce an equal share of this amount, and retains the revenues from selling the output it produces. Notice that this mechanism does not involve side payments. We claim that for a wide variety of threat games, this cartel rule works for sufficiently large cartels. We present an example which demonstrates that it can fail for small cartels, and explain how the mechanism may need to be embellished when there are few firms.

The information structure is the following. The marginal cost of production $c \in C=[\underline{c}, \bar{c}]$ is the same for all firms, but is unknown at the time production takes place. Given $c$, each firm observes a signal $s_{i}$ which is an independent draw from a common distribution, conditional on $c$, denoted $F\left(s_{i} \mid c\right)$. We assume that signals take on

\footnotetext{
${ }^{11}$ A similar problem is encountered in pure exchange settings (e.g. auctions) with common value uncertainty. In some of those settings, there has been progress characterizing optimal mechanisms with correlated information, such as by Cremer and McLean (1988). Myerson's (1981) analysis includes the special form of dependent values called "revision effects," which allows him to use reduced form auction analysis. McAfee and Reny (1988) characterize optimal mechanisms in an environment where the full information first best solution can be approximately achieved.
} 
values in the unit interval and, for all $c \in C, F(0 \mid c)=0, F(1 \mid c)=1$ and $F$ is continuous and strictly increasing on $[0,1]$. To complete the notation, let $H(c)$ be the marginal distribution on $C$ and $G\left(c \mid s_{i}\right)$ be the conditional distribution of $c$, given an observation $s_{i} \in[0,1]$.

As before, rather than specifying the exact structure of a threat game, $\theta$, we represent the threat game by the output functions induced by symmetric Bayesian equilibrium behavior of the firms. Each threat game $\theta$ with $n$ firms induces an interim profit function $\pi_{n}^{\theta}(\cdot)$ which depends on a firm's signal and an ex post output decision $q_{n}^{\theta}(\cdot)$ which depends on the vector of signals.

We say that equal share information pooling is enforceable relative to threat $\theta$ if for sufficiently large $n$ it is incentive compatible and individually rational relative to $\theta$ for all $s_{i}$. Since it is trivially incentive compatible for all $n$, we need only prove that it is individually rational for all types when $n$ is sufficiently large. Fixing $\theta$, we adopt the following notation

$$
\begin{aligned}
& \tilde{\pi}(s, c)=\left[a-c-q_{n}^{\theta}(s)\right] q_{n}^{\theta}(s) / n \quad \text { for } s \in[0,1]^{n}, \quad c \in C \\
& \pi^{n}(t)=\int_{\underline{c}}^{\bar{c}} \int_{0}^{1} \ldots \int_{0}^{1} \tilde{\pi}_{i}^{n}\left(t, s_{i}, c\right) d F\left(s_{1} \mid c\right) \ldots d F\left(s_{i-1} \mid c\right) \cdot d F\left(s_{i+1} \mid c\right) \ldots d F\left(s_{n} \mid c\right) d G(c \mid t) \\
& \pi_{M}(t)=\int_{\underline{c}}^{\bar{c}}[\max \{0,(a-c) / 2\}]^{2} d G(c \mid t) \quad \text { for all } t \in[0,1] \\
& M^{n}(\varepsilon, t)=\left\{s \in[0,1] \mid \pi^{n}(s) \geq \varepsilon \pi^{n}(t)\right\} \quad \text { for } \varepsilon>0, \quad t \in[0,1] \\
& \bar{\pi}^{n}=n \int_{\underline{c}}^{\bar{c}} \int_{0}^{1} \pi^{n}(t) d F(t \mid c) d H(c) .
\end{aligned}
$$

Thus, $\tilde{\pi}^{n}=(\cdot, \cdot)$ is the ex post profit to a firm under $\theta$ as a function of the true cost and any vector of signals; $\tilde{\pi}^{n}=(\cdot)$ is the interim expected profit to a firm under $\theta$ as a function of that firm's signal; $M^{n}(\varepsilon, t)$ is the set of firm types whose interim profits exceed $\varepsilon$ times the interim profit of a type $t$ firm; $\bar{\pi}^{n}$ is the ex ante aggregate expected profits of the group of firms under $\theta ; \pi_{M}(t)$ is a bit more difficult to interpret, but it is the interim expected profits of a monopolist who has observed signal $t \in[0,1]$, but who is permitted to produce after observing cost. For large $n$, this will approximate $n$ times the interim cartel profits of a type $t$ firm under the equal share information pooling mechanism.

DEFINITION. A threat $\theta$ is uniformly competitive if

$$
\lim _{n \rightarrow \infty} \bar{\pi}^{n}=0
$$

and for all $t \in[0,1]$ there exists $\varepsilon, \gamma>0$ such that for all $c$ and $n$

$$
\int_{M^{n}(\varepsilon, t)} d F\left(s_{i} \mid c\right)>\gamma
$$

The first part of this definition requires that aggregate ex ante profits under $\theta$ converge to 0 . The second part of the definition requires that if some firm is earning positive profits under $\theta$ then a nontrivial set of other firms is also earning positive profits. Furthermore, as $n$ gets large, this set of other firms grows at a rate on the order $n$.

THEOREM 6. If $\theta$ is uniformly competitive, then equal-share information pooling is an enforceable cartel. 
We illustrate the above result with the following example. Let $\theta$ be the interim Cournot quantity game. Let there be two equally-likely possible costs $C=\{0,3\}$ with $h(0)=1 / 2, h(3)=1 / 2$. Let $a=1$, and let the conditional density of signals be given by

$$
f\left(s_{i} \mid c=0\right)=\left\{\begin{array}{ccc}
\delta & \text { if } & s_{i}<1 / 2 \\
2-\delta & \text { if } & s_{i} \geq 1 / 2
\end{array} \quad f\left(s_{i} \mid c=3\right)=\left\{\begin{array}{ccc}
\delta^{2} & \text { if } & s_{i}<1 / 2 \\
2-\delta^{2} & \text { if } & s_{i} \geq 1 / 2
\end{array}\right.\right.
$$

where $\delta \in(0,1)$ is a small positive number. Therefore for small $\delta$, low signals are rare, quite optimistic, and highly informative, whereas high signals are common, mildly pessimistic, and uninformative.

With two firms it can be shown that for small $\delta$, the following is an equilibrium:

$$
q^{2}\left(s_{i}\right)=\left\{\begin{array}{ccc}
\frac{(1+\delta)-3 \delta}{2(1+\delta)+\delta\left(1+\delta^{2}\right) / 2} & \text { if } & s_{i}<1 / 2 \\
0 & \text { if } & s_{i} \geq 1 / 2
\end{array}\right.
$$

In the limit as $\delta \rightarrow 0$. since completely uninformed firms would produce 0 , a low-signal firm is able to act as a monopolist in the low-cost state and produces $1 / 2$. Its expected profit is approximately $1 / 4$. It is not individually rational for a low signal type to participate in the equal share information pooling cartel, since such a firm would have to part with (almost) half of its (almost) monopoly profit.

With $n$ firms, the unique equilibrium is

$$
q^{n}\left(s_{i}\right)=\left\{\begin{array}{ccc}
\frac{(1+\delta)-3 \delta}{2(1+\delta)+(n-1) \delta\left(1+\delta^{2}\right) / 2} & \text { if } & s_{i}<1 / 2 \\
0 & \text { if } & s_{i} \geq 1 / 2
\end{array}\right.
$$

Expected profit equals $\left(q^{n}\right)^{2}$ which converges to 0 on the order of $n^{2}$, so $n \pi^{n}(t) \rightarrow 0$ for all $t$. Expected cartel profits for a low-signal firm converges to $(1 / 4) /(1+\delta)>0$. Expected cartel profits for a high-signal firm converge to $(1 / 4)(2-\delta) /\left(4-\delta-\delta^{2}\right)>0$.

It is interesting to note that, while the equal sharing rule does not work for small $n$, a rule in which one's share is an explicit function of the vector of reported signals is individually rational and incentive compatible in this example, at least for small $n$. Under this rule, firms who submit a low signal are asked to produce a large proportion of the output. In particular, the share equals 0 if a firm submits a high signal and $1 / k$ otherwise, where $k$ is the number of firms submitting a low signal. This suggests that the ability for a cartel to enforce the joint monopoly solution with only common value uncertainty is even more general than we have established here, where we have limited attention to mechanisms in which shares are independent of reports.

We have presented a simple model of cartel enforcement in an effort to determine how uncertainty about costs might limit the power of a cartel to enforce desirable outcomes. Several strong assumptions have been made in order to keep the analysis manageable. In this section, we discuss the effects of alternative assumptions.

No Side-Payments. If side payments are not allowed, then the revenue rule must equal the actual revenue for each firm: $r_{i}(c)=\left[a-\sum q_{i}(c)\right] q_{i}(c)$. With this restriction, the set of enforceable cartels is greatly diminished. Roberts $(1983,1985)$ has explored this problem and has shown that typically with private cost uncertainty the monopoly outcome is not attainable, since every firm has an incentive to understate its cost, so as to increase its expected production. However, with common cost uncertainty, our results for the equal-share information pooling rule continue to hold.

Entry. We have exogenously fixed the number of firms. But since high-cost firms earn a substantial profit from participating in the cartel, there is an incentive for new firms to enter the industry simply to collect the bribe not to produce. If the industry is unable to prevent entry, then it is critical that a mechanism that discourages entry be adopted: profits to high-cost firms must be less than the cost of entry. In our problem this implies that the highest cost firm must earn 0 profits in the mechanism. Such a constraint on the mechanism avoids the freerider problem, but also implies (due to Lemma 4) that the monopoly outcome is unattainable whenever entry costs are low, even under $\alpha$-majority rule. 
A similar problem is addressed in the context of collusion in a private value auction by McAfee and McMillan (1987) who show that, with free entry, the best colluding bidders can do for all to bid the seller's reserve price, implying a random allocation of the good. This would be analogous in our model to the cartel randomly awarding monopoly rights to one firm. However, this does not satisfy individual rationality, for either the Cournot or the Bertrand threat in our model with two firms and costs uniformly distributed. In that case, in contrast a random selection of a monopolist gives a $c=0$ type an expected profit of $1 / 8$. The Cournot threat yields interim profits of

$$
\left[1+2^{.5}\right]^{-2}>.125
$$

for a $c=0$ type; the Bertrand threat yields an interim profit of $5 / 24>1 / 8$. Therefore, the random selection process is not individually rational relative to either of these threats. It is an open question, even for the special case of duopoly with uniform costs what the best incentive compatible individually rational cartel agreement is that does not provide adverse entry incentives.

Learning from Disagreement. Suppose that before reporting costs each firm simultaneously votes for or against the proposed cartel $\langle q, r\rangle$. Under $\alpha$-majority rule, if the cartel is not approved by $\alpha n$ firms, then the threat outcome $\theta$ results. In deriving the threat $\theta$, we have assumed that nothing is learned from the voting process, since the threat payoffs are determined using the prior beliefs. Alternatively, one might suppose that firms make inferences in the face of disagreement. In particular, it seems plausible that if a firm votes against the cartel, it did so because it gained the least from participation. Since we have shown that low-cost firms benefit the least from cartel coordination, cartel members should associate negative votes with low-cost firms. The effect of these inferences on behavior in the threat game depends upon whether the costs are private or common.

Consider for example the Cournot threat game. In the private costs model, inferences from an observation that some firm has voted against the cartel rule would have the effect of reducing everyone else's output in the threat game, since they expect high output from the disagreeing firm. The net effect, then, is to weaken the threat of disagreement, and therefore to reduce the set of enforceable cartels. This leads us to conjecture that if the monopoly outcome is not enforceable with a passive inference from disagreement, it is still not enforceable when learning is allowed.

In the common costs model, inferences are likely to have the opposite effect. Here, the worst off types will be the ones with optimistic signals. If firms infer that anyone voting against the cartel has an optimistic signal, then they will respond by expanding their output, since it is likely that the true cost is lower than they had originally estimated. This more aggressive response in the face of a negative vote makes the threat game relatively less attractive to any type. Thus in the common values case, we would conjecture that the monopoly outcome will still be enforceable with learning from disagreement, whenever it is enforceable with passive inference.

Learning from disagreement is only an issue if the behavior (and hence the payoffs) in the threat game are influenced by the inferences, as is true in the Cournot threat game. Other threat games, such as our (ex post) Bertrand threat or exclusion from the industry (zero profits), yield outcomes that are not affected by beliefs, so that inferences do not alter the individual rationality constraints. A more general and detailed analysis of learning from disagreement is found in Cramton and Palfrey (1989).

Increasing Costs or Risk Aversion. With increasing costs or risk aversion, the characterization result in Theorem 1 becomes much more difficult, since linearity is lost. Some insights into analyzing this more complex problem may be gleaned from the literature on auction design with risk averse bidders, for example Maskin and Riley (1984). An advantage of the increasing cost model is that ex post efficiency may demand that more than one firm produce in the industry.

Regulated Cartel. The objective of a cartel in this paper is to maximize producer surplus. If instead the cartel is formed and regulated by the government, then it seems likely that both producer and consumer surplus would be given positive weight in the objective function. An analysis of this problem would extend the work of Baron and Myerson (1982) from one to several firms.

Ex Ante Efficient Cartels. For the private cost model we were able to characterize under what circumstances an enforceable cartel can achieve the monopoly outcome, but when the monopoly outcome is not attainable, how much collusion is possible? Moreover, what cartel rules generate the largest industry profits? These questions may be particularly interesting to examine in the context of few firms. In the case of many firms, we conjectured that the ex ante efficient enforceable cartel is often bounded strictly away from the joint monopoly cartel. The 
example in Table 1 suggests this, as the threat game becomes progressively more attractive to the worst off type relative to the joint monopoly solution when the number of firms gets large.

Yale School of Management, U.S.A.

California Institute of Technology, U.S.A.

APPENDIX

PROOFS

ProOF OF LEMMA 1. Only if. If $\langle q, r\rangle$ is incentive compatible, then

or equivalently

$$
\pi_{i}\left(c_{i}\right)=R_{i}\left(c_{i}\right)-c_{i} Q_{i}\left(c_{i}\right) \geq R_{i}(\mathrm{v})-c_{i} Q_{i}(\mathrm{v}),
$$

$$
\pi_{i}\left(c_{i}\right) \geq \pi_{i}(v)-\left(c_{i}-v\right) Q_{i}(v),
$$

implying that $\pi_{i}$ has a supporting hyperplane at $v$ with slope $-Q_{i}(v) \leq 0$. Thus, $\pi_{i}$ is convex and has derivative $d \pi_{i} / d c_{i}=-Q_{i}$ almost everywhere. Also, $Q_{i}$ must be decreasing, and

$$
\pi_{i}\left(c^{\prime}\right)-\pi_{i}\left(c_{i}\right)=-\int_{c_{i}}^{c^{\prime}} v d Q_{i}(v) .
$$

(We use the Stieltjes integral throughout this paper, so that any discontinuities in the expected production function $Q_{i}$ are accounted for in the integral.) By integration by parts,

$$
\int_{c_{i}}^{c^{\prime}} Q_{i}(v) d v=c^{\prime} Q_{i}\left(c^{\prime}\right)-c_{i} Q_{i}\left(c_{i}\right)-\int_{c_{i}}^{c^{\prime}} v d Q_{i}(v),
$$

which together with the definition of $\pi_{i}$ yields $(I C)$.

If. Subtracting the identity

$$
c_{i}\left[Q_{i}\left(c^{\prime}\right)-Q_{i}\left(c_{i}\right)\right]=c_{i} \int_{c_{i}}^{c^{\prime}} d Q_{i}\left(c_{i}\right) d c i
$$

from $(I C)$ results in

$$
R_{i}\left(c^{\prime}\right)=R_{i}\left(c_{i}\right)-c_{i} Q_{i}\left(c^{\prime}\right)+c_{i} Q_{i}\left(c_{i}\right)=\int_{c_{i}}^{c^{\prime}}\left(v-c_{i}\right) d Q_{i}\left(c_{i}\right) \leq 0,
$$

where the inequality follows because the integrand is nonpositive for all $c_{i}$ and $v \in\left[c_{i}, \bar{c}\right]$, since $Q_{i}$ is decreasing. Rearranging the terms on the left-hand side yields

$$
R_{i}\left(c_{i}\right)-c_{i} Q_{i}\left(c_{i}\right) \geq R_{i}\left(c^{\prime}\right)-c_{i} Q\left(c^{\prime}\right),
$$

which is incentive compatibility.

PROOF OF LEMMA 2. It is necessary and sufficient to check individual rationality at costs which minimize a firm's net payoff $U_{i}^{\theta}\left(c_{i}\right)=\pi_{i}\left(c_{i}\right)-\pi^{\theta}\left(c_{i}\right)$, since if individual rationality is satisfied for the worst-off types of firms it is satisfied for all types. The continuity of both $\pi_{i}$ and $\pi^{\theta}$ implies that $U_{i}^{\theta}\left(c_{i}\right)$ has a minimum over $c_{i} \in[\underline{c}, \bar{c}]$. Taking the derivative of $U_{i}^{\theta}\left(c_{i}\right)$ with respect to $c_{i}$ and applying from Lemma 1 that $d \pi_{i} / d c_{i}=-Q_{i}$ and $d \pi^{\theta} / d c_{i}=-Q^{\theta}$ almost everywhere yields the first-order necessary condition for an interior minimum: ${ }^{12}$

$$
Q_{i}\left(\hat{c}_{i}\right)=Q^{\theta}\left(\hat{c}_{i}\right)
$$

\footnotetext{
${ }^{12}$ To simplify notation, we assume that both $Q_{i}$ and $Q^{\theta}$ are continuous.
} 
The worst-off type must either be at an extreme point ( $\underline{c}$ or $\bar{c})$ or at an interior point satisfying $(\hat{C})$.

The following result, not stated in the body of the paper, is a more general version of Theorem 1 , which applies to asymmetric as well as symmetric production rules. If production rules are symmetric, then it reduces to Theorem 1.

LEMMA 3. For any production rule $q \geq 0$, there exists a revenue rule $r$ such that the cartel $\langle q, r\rangle$ is enforceable if and only if $Q_{i}(\cdot)$ is decreasing and for all $\hat{c}_{i} \in \hat{C}_{i}$

$$
\sum_{i=1}^{n}\left[R_{i}(\bar{c})-\bar{c} Q_{i}(\bar{c})+\int_{\hat{c}_{i}}^{\bar{c}} Q_{i}(v) d v\right] \geq \sum_{i=1}^{n} \pi^{\theta}\left(\hat{c}_{i}\right)
$$

where

$$
\sum_{i=1}^{n} R_{i}(\bar{c})=E[\rho(c)]+\sum_{i=1}^{n} \int_{\underline{c}}^{\bar{c}} v F(v) d Q_{i}(v)
$$

ProOF. Only if. Suppose $\langle q, r\rangle$ is incentive compatible and individually rational. Then from Lemma 1, for any $c^{\prime}$ and $c_{i}$

$$
R_{i}\left(c^{\prime}\right)=R_{i}\left(c_{i}\right)-\int_{c^{\prime}}^{c_{i}} v d Q_{i}(v)
$$

Integrating over all types in $[\underline{c}, \bar{c}]$ yields

$$
\begin{aligned}
E_{i}\left\{R_{i}\left(c^{\prime}\right)\right\} & =R_{i}\left(c_{i}\right)-\int_{c^{\prime}=\underline{c}}^{\bar{c}} \int_{v=c^{\prime}}^{c_{i}} v d Q_{i}(v) d F\left(c^{\prime}\right) \\
= & R_{i}\left(c_{i}\right)+\int_{v=c_{i}}^{\bar{c}} \int_{c^{\prime}=v}^{\bar{c}} d F\left(c^{\prime}\right) v d Q_{i}(v)-\int_{v=\underline{c}}^{c_{i}} \int_{c^{\prime}=\underline{c}}^{v} d F\left(c^{\prime}\right) v d Q_{i}(v) \\
= & R_{i}\left(c_{i}\right)+\int_{c_{i}}^{\bar{c}}[1-F(v)] v d Q_{i}(v)-\int_{\underline{c}}^{c_{i}} F(v) v d Q_{i}(v) .
\end{aligned}
$$

where the second line follows from changing the order of integration. Budget balance requires that

$$
\sum_{i=1}^{n} r_{i}(c)=\rho(c) \quad \text { for all } c \in[\underline{c}, \bar{c}]^{n}
$$

so we have

$$
\sum_{i=1}^{n} E_{i}\left\{R_{i}\left(c^{\prime}\right)\right\}=E\left\{\sum_{i=1}^{n} r_{i}(c)\right\}=E[\rho(c)] .
$$

Therefore, summing over all firms yields

$$
\sum_{i=1}^{n} R_{i}\left(c_{i}\right)=E[\rho(c)]+\sum_{i=1}^{n}\left[\int_{\underline{c}}^{c_{i}} F(v) v d Q_{i}(v)-\int_{c_{i}}^{\bar{c}}[1-F(\mathrm{v})] \mathrm{v} d Q_{i}(\mathrm{v})\right]
$$

Evaluating $(T)$ at $c_{i}=\bar{c}$ results in $(R)$. Integrating $(I C)$ by parts and letting $c^{\prime}=\bar{c}$ and $c^{\prime}=\hat{c}_{i}$ yields

$$
R_{i}\left(\hat{c}_{i}\right)=R_{i}(\bar{c})-\bar{c} Q_{i}(\bar{c})+\hat{c}_{i} Q_{i}\left(\hat{c}_{i}\right)+\int_{\hat{c}_{i}}^{\bar{c}} Q_{i}(v) d v
$$

From Lemma 2, $R_{i}\left(\hat{c}_{i}\right)-\hat{c}_{i} Q_{i}\left(\hat{c}_{i}\right) \geq \pi^{\theta}\left(\hat{c}_{i}\right)$, which implies 


$$
\sum_{i=1}^{n}\left[R_{i}\left(\hat{c}_{i}\right)-\hat{c}_{i} Q_{i}\left(\hat{c}_{i}\right)\right] \geq \sum_{i=1}^{n} \pi^{\theta}\left(\hat{c}_{i}\right)
$$

Substituting $(\hat{\mathrm{T}})$ into the expression above yields $(E)$.

If. The proof is by construction. Let

$$
r_{i}(c)=t_{i}+\rho_{i}(c)+\int_{\underline{c}}^{c_{j}} v d Q_{i}(v)-\frac{1}{n-1} \sum_{j \neq i} \int_{\underline{c}}^{c_{j}} v d Q_{j}(v)
$$

where

$$
\rho_{i}(c)=\frac{1}{n}\left[\rho(c)-E_{-i}[\rho(c)]+\frac{1}{n-1} \sum_{j \neq i} E_{-j}[\rho(c)] .\right.
$$

Then $\sum \rho_{i}(c)=\rho(c)$ and $E_{-i}\left[\rho_{i}(c)\right]=\frac{1}{n} E[\rho(c)]$. After changing the order of integration,

$$
R_{i}\left(c_{i}\right)=t_{i}+\frac{1}{n} E[\rho(c)]+\int_{\underline{c}}^{c_{i}} v d Q_{i}(v)-\frac{1}{n-1} \sum_{j \neq i} \int_{\underline{c}}^{\bar{c}}[1-F(v)] v d Q_{j}(v),
$$

so Lemma 1 guarantees that $\langle q, r\rangle$ is incentive compatible. Finally, we have individual rationality if and only if $R_{i}\left(\hat{c}_{i}\right)-\hat{c}_{i} Q_{i}\left(\hat{c}_{i}\right) \geq \pi^{\theta}\left(\hat{c}_{i}\right)$ by Lemma 2. Budget balance requires $\sum r_{i}(c)=\rho(c)$, which implies $\sum t_{i}=0$. Our hypothesis is that $(E)$ is satisfied, which is equivalent to

hence, if we let

$$
\sum\left[R_{i}\left(\hat{c}_{i}\right)-\hat{c}_{i} Q_{i}\left(\hat{c}_{i}\right)\right] \geq \sum \pi^{\theta}\left(\hat{c}_{i}\right)
$$

$$
t_{i}=\frac{1}{n} \sum_{i=1}^{n} R_{i}\left(\hat{c}_{i}\right)-\int_{\underline{c}}^{\hat{c}_{i}} v d Q_{i}(v)+\frac{1}{n-1} \sum_{i=1}^{n} \int_{\underline{c}}^{\bar{c}}[1-F(v)] v d Q_{j}(v),
$$

then $R_{i}\left(\hat{c}_{i}\right)=1 / n \Sigma R_{i}\left(\hat{c}_{i}\right) \geq \pi^{\theta}\left(\hat{c}_{i}\right)+\hat{c}_{i} Q_{i}\left(\hat{c}_{i}\right)$.

ProOF OF THEOREM 1 . Given that $Q_{i}(\cdot)=Q_{j}(\cdot) \equiv Q(\cdot)$ for all $i, j \in N$, it immediately follows from Lemma 3 that $\left(E^{\prime}\right)$ and $\left(R^{\prime}\right)$ are equivalent to $(E)$ and $(R)$ of Theorem 1.

ProOf OF LeMMA 4. From Theorem 1, symmetry implies:

$$
R^{M}(\bar{c})=\frac{1}{n} E[\rho(c)]+\int_{\underline{c}}^{\bar{c}} v F(v) d Q^{M}(v) .
$$

For the monopoly mechanism, we have

$$
\frac{1}{n} E[\rho(c)]=\frac{1}{n} \int_{\underline{c}}^{\bar{c}} \frac{1}{4}(a-v)(a+v) n f(v)[1-F(v)]^{n-1} d v
$$

and

$$
\begin{aligned}
\int_{\underline{c}}^{\bar{c}} v F(v) d Q^{M}(v) & =\left.v F(v) d Q^{M}(v)\right|_{\underline{c}} ^{\bar{c}}-\int_{\underline{c}}^{\bar{c}}[F(v)+v f(v)] Q_{M}(v) d v \\
& =0-\int_{\underline{c}}^{\bar{c}}[F(v)+v f(v)] \frac{1}{2}(a-v)[1-F(v)]^{n-1} d v
\end{aligned}
$$

Collecting terms gives, 


$$
R^{M}(\bar{c})=\int_{\underline{c}}^{\bar{c}}\left[\frac{1}{4}(a-v)(a+v) f(v)-[F(v)+v f(v)] \frac{1}{2}(a-v)\right][1-F(v)]^{n-1} d v,
$$

and so

$$
R^{M}(\bar{c})=\int_{\underline{c}}^{\bar{c}} \frac{1}{4}(a-v)^{2} f(v)[1-F(v)]^{n-1} d v-\int_{\underline{c}}^{\bar{c}} \frac{1}{2}(a-v) F(v)[1-F(v)]^{n-1} d v .
$$

Next, integrating the second term by parts yields

$$
\begin{aligned}
& \int_{\underline{c}}^{\bar{c}} \frac{1}{2}(a-v) F(v)[1-F(v)]^{n-1} d v=-\frac{1}{4}(a-v)^{2} F(v)[1-F(v)]^{n-1} \mid \begin{array}{l}
\bar{c} \\
\underline{c}
\end{array} \\
& +\int_{\underline{c}}^{\bar{c}} \frac{1}{4}(a-v)^{2}\left[f(v)[1-F(v)]^{n-1}-f(v) F(v)(n-1)[1-F(v)]^{n-2}\right] d v \\
& \left.=\int_{\underline{c}}^{\bar{c}} \frac{1}{4}(a-v)^{2} f(v)[1-F(v)]^{n-1} d v-\int_{\underline{c}}^{\bar{c}} \frac{1}{4}(a-v)^{2} f(v) F(v)(n-1) \cdot[1-F(v)]^{n-2}\right] d v .
\end{aligned}
$$

Substituting this back into $(R$ ”), we get $(\bar{R})$. This is an equal share of the expected industry profit if the second lowest cost firm produces the monopoly output, since $n(n-1) f(v) F(v)[1-F(v)]^{n-2}$ is the density of the secondorder statistic.

PROOF OF LEMMA 5. In the Cournot game, firm $i$ seeks to maximize its expected profit given the output decisions of the other firms. Firm $i$ 's profit $\pi^{C}\left(c_{i}\right)$ is given by

$$
\pi^{C}\left(c_{i}\right)=\left(\bar{c}-c_{i}-Q_{i}\right) Q_{i}
$$

where $\bar{c}=a-(n-1) \bar{Q}$ and $\bar{Q}$ is the expected value of $Q_{i}$. Taking the derivative of the profit function with respect to $Q_{i}$ yields the first-order condition

$$
Q_{i}=\frac{1}{2}\left(\bar{c}-c_{i}\right)
$$

Checking the boundary conditions we see that firm i's output is given by

$$
Q_{i}=Q^{C}\left(c_{i}\right)= \begin{cases}0 & \text { if } c_{i} \geq \tilde{c} \\ \frac{1}{2}\left(\tilde{c}-c_{i}\right) & \text { if } c_{i}<\tilde{c} .\end{cases}
$$

Substituting $Q_{i}$ into $\left(\pi C^{\prime}\right)$ yields $(\pi C)$. Moreover,

$$
\bar{Q}=E\left(Q_{i}\right)=\frac{1}{2} \int_{\underline{c}}^{\bar{c}}(\tilde{c}-v) d F(v)=\frac{1}{2} \int_{\underline{c}}^{\bar{c}} F(v) d v
$$

Substituting $\bar{Q}$ into the definition of $\bar{c}$ yields the implicit condition $(\bar{C})$ for $\bar{c}$, which determines a unique $\tilde{c}$ since the left-hand side of $(\bar{C})$ is strictly decreasing, the right-hand side is strictly increasing, and the left-hand side is greater than the right-hand side at $\tilde{c}=\underline{c}$, and the left-hand side is less than the right-hand side at $\bar{c}$ if and only if $2(a-\bar{c}) \geq(n-1)[\bar{c}-E(c)]$.

PROOF OF LEMMA 6. Let $c_{l}$ be the lowest cost among the $n$ firms and let $c_{s}$ be the second-lowest cost. Under Bertrand competition price falls to the second lowest cost, $c_{s}$, or the monopoly price of the lowest-cost firm, $\frac{1}{2}\left(a+c_{l}\right)$, whichever is less.

Thus, firm $i$ 's ex post production is 


$$
q_{i}^{B}\left(c_{i}\right)= \begin{cases}0 & \text { if } c_{i}>c_{l} \\ a-c_{s} & \text { if } c_{i}=c_{l} \text { and } c_{s} \leq \frac{1}{2}\left(a+c_{l}\right) \\ \frac{1}{2}\left(a-c_{i}\right) & \text { if } c_{i}=c_{l} \text { and } c_{s}>\frac{1}{2}\left(a+c_{l}\right) .\end{cases}
$$

Firm $i$ has the lowest cost if the cost of each of the other $n-1$ firms is greater than $c_{i}$, so

$$
\operatorname{Pr}\left\{\min _{i \neq j} c_{j}>c_{i}\right\}=\left[1-F\left(c_{i}\right)\right]^{n-1} \equiv G\left(c_{i}\right) \text {. }
$$

The interim production for firm $i$ is then found by integrating over the possible costs of the second-lowest cost firm:

$$
Q^{B}\left(c_{i}\right)=-\int_{c_{i}}^{1 / 2\left(a+c_{i}\right)}(a-v) d G(\mathrm{v})-\int_{1 / 2\left(a+c_{i}\right)}^{\bar{c}} \frac{1}{2}\left(a-c_{i}\right) d G(\mathrm{v}) .
$$

Performing the integration (by parts) results in

$$
Q^{B}\left(c_{i}\right)=a\left[G\left(c_{i}\right)-G\left(\frac{1}{2}\left(a+c_{i}\right)\right)\right]+\left.v G(v)\right|_{c_{i}} ^{1 / 2\left(a+c_{i}\right)}-\int_{c_{i}}^{1 / 2\left(a+c_{i}\right)} G(v) d v+\frac{1}{2}\left(a-c_{i}\right) G\left(\frac{1}{2}\left(a+c_{i}\right)\right)
$$

which after simplifying yields $(Q B)$. Similar calculations lead to $(\pi \mathrm{B})$.

ProOf OF THEOREM 2. With the monopoly outcome and a Cournot threat, $(M C)$ is equivalent to $\left(E^{\prime}\right)$, since $Q^{M}(\bar{c})=0$. Hence, Theorem 2 is equivalent to Theorem 1, except that individual rationality is only checked at the interior point $\hat{c}$. It suffices to show that individual rationality cannot be violated at either extreme point $\underline{c}$ or $\bar{c}$. Lemma 4 implies that individual rationality is not violated for firm $\bar{c}$, since $\pi^{M}(\bar{c})>\pi^{C}(\bar{c})$. Since $Q^{M}(\underline{c})=\frac{1}{2}(a-\underline{c})$ and $Q^{C}(\underline{c})=\frac{1}{2}(\bar{c}-\underline{c}), Q^{M}(\underline{c})>Q^{C}(\underline{c})$ so the firm's net payoff $U^{C}(\cdot)$ is decreasing at $\underline{c}$. Thus, $\underline{c}$ is not the worst-off type.

PROOF OF THEOREM 3. With the monopoly outcome and a Bertrand threat, $(M B)$ is equivalent to $\left(E^{\prime}\right)$ evaluated at $\underline{c}$. Hence, it suffices to show that the worst-off type of firm is $\underline{c}$. A firm's net payoff $U^{B}(\cdot)$ is increasing if and only if $Q^{M}\left(c_{i}\right) \leq Q^{B}\left(c_{i}\right)$; that is,

$$
\frac{1}{2}\left(a-c_{i}\right) G\left(c_{i}\right) \leq\left(a-c_{i}\right) G\left(c_{i}\right)-\int_{c_{i}}^{1 / 2\left(a+c_{i}\right)} G(v) d v,
$$

or equivalently,

$$
\frac{1}{2}\left(a-c_{i}\right) \geq \int_{c_{i}}^{1 / 2\left(a+c_{i}\right)} \frac{G(v)}{G\left(c_{i}\right)} d v
$$

But this inequality is always satisfied, since $G(v) / G\left(c_{i}\right) \leq 1$ for all $v \geq c_{i}$. Therefore, $U^{B}(\cdot)$ is everywhere increasing, so the worst-off type must be $\underline{c}$. 
Proof OF THEOREM 4. From Lemma 4,

$$
\begin{aligned}
R^{M}(\bar{c}) & =\int_{\underline{c}}^{\bar{c}} \frac{1}{4}(a-v)^{2}(n-1) f(v) F(v)[1-F(v)]^{n-2} d v \\
& =\frac{1}{n}\left(\frac{a-c}{2}\right)^{2}-\int_{\underline{c}}^{\bar{c}} \frac{1}{2}(a-v)\left[\frac{1}{n} G_{n}(v)+F(v) G_{n-1}(v)\right] d v,
\end{aligned}
$$

and

$$
\int_{\underline{c}}^{\bar{c}} Q^{M}(v) d v=\int_{\underline{c}}^{\bar{c}} \frac{1}{2}(a-v) G_{n-1}(v) d v
$$

where $G_{n}(v)=[1-F(v)]^{n}$. Hence,

$$
\begin{aligned}
R^{M}(\bar{c})+\int_{\underline{c}}^{\bar{c}} Q^{M}(v) d v & =\frac{1}{n}\left(\frac{a-\underline{c}}{2}\right)^{2}+\frac{n-1}{n} \int_{\underline{c}}^{\bar{c}}\left(\frac{a-v}{2}\right) G_{n}(v) d v \\
& =\left(\frac{a-\underline{c}}{2}\right)^{2}-\frac{n-1}{n} \int_{\underline{c}}^{\bar{c}}\left(\frac{a-v}{2}\right)^{2} g_{n}(v) d v
\end{aligned}
$$

where $g_{n}(v)=n f(v)[1-F(v)]^{n-1}$. In addition,

$$
\pi^{B}(\underline{c})=\int_{\underline{c}}^{\gamma} 2(\gamma-v) G_{n-1}(v) d v=\left(\frac{a-\underline{c}}{2}\right)^{2}-\int_{\underline{c}}^{\gamma}\left[\frac{a-v}{2}-\frac{v-\underline{c}}{2}\right]^{2} g_{n-1}(v) d v,
$$

where $\gamma=(a+\underline{c}) / 2$. Therefore, from Theorem 3, the monopoly outcome is not enforceable with the Bertrand threat if and only if

or equivalently

$$
\frac{n-1}{n} \int_{\underline{c}}^{\bar{c}}\left(\frac{a-v}{2}\right)^{2} g_{n}(v) d v>\int_{\underline{c}}^{\gamma}\left[\frac{a-v}{2}-\frac{v-\underline{c}}{2}\right]^{2} g_{n-1}(v) d v,
$$

which holds if

$$
\int_{\underline{c}}^{\bar{c}}\left(\frac{a-v}{2}\right)^{2}[1-F(v)] g_{n-1}(v) d v>\int_{\underline{c}}^{\gamma}\left[\frac{a-v}{2}-\frac{v-\underline{c}}{2}\right]^{2} g_{n-1}(v) d v,
$$

$$
\int_{\underline{\underline{c}}}^{\gamma}\left(\frac{a-v}{2}\right)^{2}[1-F(v)] g_{n-1}(v) d v>\int_{\underline{\underline{c}}}^{\gamma}\left[\frac{a-v}{2}-\frac{v-\underline{c}}{2}\right]^{2} g_{n-1}(v) d v
$$

Since $a-v>v-\underline{c}>0$ for $v \in[\underline{c}, \gamma]$ the last inequality holds if and only if

$$
\begin{aligned}
& \int_{\underline{c}}^{\gamma}\left(\frac{a-v}{2}\right)^{2}[1-F(v)] g_{n-1}(v) d v \\
& \quad>\int_{\underline{c}}^{\gamma}\left(\frac{a-v}{2}\right)^{2} g_{n-1}(v) d v-\int_{\underline{c}}^{\gamma}\left(\frac{v-\underline{c}}{2}\right)\left(\frac{2 a+\underline{c}-3 v}{2}\right) g_{n-1}(v) d v,
\end{aligned}
$$

or equivalently

$$
\int_{\underline{c}}^{\gamma}\left(\frac{a-v}{2}\right)^{2} F(v) g_{n-1}(v) d v-\int_{\underline{c}}^{\gamma}\left(\frac{v-\underline{c}}{2}\right)\left(\frac{2 a+\underline{c}-3 v}{2}\right) g_{n-1}(v) d v,
$$


which holds for large $n$ if for $v$ sufficiently close to $\underline{c}$,

$$
\left(\frac{a-v}{2}\right)^{2} F(v)<\left(\frac{v-\underline{c}}{2}\right)\left(\frac{2 a+\underline{c}-3 v}{2}\right)
$$

To see this, let

$$
D(v)=\left(\frac{a-v}{2}\right)^{2} F(v)-\left(\frac{v-\underline{c}}{2}\right)\left(\frac{2 a+\underline{c}-3 v}{2}\right) .
$$

The condition $(D)$ amounts to saying that there exists $c^{0}>\underline{c}$ such that for all $v \in\left(\underline{c}, c^{0}\right], D(v)<0$. Denote $\varepsilon \equiv \min _{v \in\left[c^{0} / 2, c^{0}\right]}|D(v)|$ and let $M \equiv \max _{v \in\left(c^{0}, \gamma\right)}|D(v)|$. Then

$$
\begin{aligned}
\int_{\underline{c}}^{\gamma} D(v) & g_{n-1}(v) d v \\
& =\int_{\underline{c}}^{c^{0} / 2} D(v) g_{n-1}(v) d v+\int_{c^{0} / 2}^{c^{0}} D(v) g_{n-1}(v) d v+\int_{c^{0}}^{\gamma} D(v) g_{n-1}(v) d v, \\
& <\int_{\underline{c}}^{c^{0} / 2} D(v) g_{n-1}(v) d v-\varepsilon\left(\left[1-F\left(c^{0} / 2\right)\right]^{n-1}-\left[1-F\left(c^{0}\right)\right]^{n-1}\right)+M\left[1-F\left(c^{0}\right)\right]^{n-1} \\
& =\int_{\underline{c}}^{c^{0} / 2} D(v) g_{n-1}(v) d v-\left(\left[1-F\left(c^{0} / 2\right)\right]^{n-1}-\left[1-F\left(c^{0}\right)\right]^{n-1}\right) \\
& \left(\varepsilon-M \frac{1}{\left[\left(1-F\left(c^{0} / 2\right)\right) /\left(1-F\left(c^{o}\right)\right)\right]^{n-1}-1}\right)
\end{aligned}
$$

$<0$ for large $n$, since $F\left(c^{0} / 2\right)<F\left(c^{0}\right)$ implies that

$$
\lim _{n \rightarrow \infty} \frac{1}{\left[\left(1-F\left(c^{0} / 2\right)\right) /\left(1-F\left(c^{o}\right)\right)\right]^{n-1}-1}=0 .
$$

A sufficient condition for $(D)$ to hold is that $F$ is unconcentrated at $\underline{c}$, since for $v$ sufficiently close to $\underline{c}$

$$
F(v)<\frac{2(v-\underline{c})}{a-\underline{c}}<\frac{(v-\underline{c})(2 a+\underline{c}-3 v)}{(a-v)^{2}},
$$

where the second inequality follows from routine calculation.

\section{PROOF OF LEMMA 7. Trivial.}

Proof of TheOREM 5. From Lemma 4, the interim profit of the $\bar{c}$ firm from participation in the ex post efficient cartel, $n \pi_{n}^{M}(\bar{c})$, equals the expected profit of the cartel if the second most efficient firm were to produce its monopoly outcome and all other firms were to produce nothing. This converges in the limit to $[(a-\underline{c}) / 2]^{2}$. This is true as well for all other firms with costs less than $\bar{c}$ but greater than $\underline{c}$. But if $\theta$ is uniformly nonmonopolistic, then for any fixed $\alpha, \varepsilon$, and $\delta$, there is a sufficiently large $N$ such that for all $n>N$ the expected proportion of firms for which $\left.{ }^{\theta}+\varepsilon[(a-\underline{c}) / 2]^{2} \quad \alpha\right)-$, so the optimal cartel rule is $\alpha$ individually rational under $\theta$

P $\quad \mathrm{T} \quad 6$. We need to show that for large $n$,

$\theta$ for all $t \quad[0,1]$. First, note that $\pi\left(t \quad q^{n} t\right)=0$ for all , so the cartel is individually rational for these firms. Therefore, suppose that ${ }_{M}()>0$. With information pooling, the interim joint monopoly profits, 


\section{CARTEL ENFORCEMENT}

conditional on $s$

$\left.\pi_{M} t\right)$. Therefore, individual rationality will be satisfied for if, for sufficiently large $n, \lim _{n \rightarrow \infty} n \pi^{n}(t)<\pi_{M}(t)$.

We next show that the left-hand side of this inequality converges to 0 if $\theta$ is uniformly competitive. From definitions,

$$
\begin{aligned}
\bar{\pi}^{n} & =n \int_{\underline{c}}^{\bar{c}} \int_{0}^{1} \pi^{n}(s) d F(s \mid c) d H(c) \\
& \geq n \int_{\underline{c}}^{\bar{c}} \int_{M^{n}(\varepsilon, t)} \pi^{n}(s) d F(s \mid c) d H(c) \\
& \geq n \int_{\underline{c}}^{\bar{c}} \varepsilon \pi^{n}(t) \int_{M^{n}(\varepsilon, t)} d F(s \mid c) d H(c) \\
& \geq n \varepsilon \gamma \pi^{n}(t) .
\end{aligned}
$$

Hence, $n \pi^{n}(t)<\bar{\pi}^{n} / \varepsilon \gamma$ for all $n$. Therefore, by $(q 1)$

$$
\lim _{n \rightarrow \infty} n \pi^{n}(t)=0
$$

\section{REFERENCES}

ABREU, D., "Extremal Equilibria of Oligopolistic Supergames," Journal of Economic Theory 39 (1986), 91-225

, D. PEARCE AND E. STACCHETTI, "Optimal Cartel Equilibria with Imperfect Monitoring," Journal of Economic Theory 39 (1986), 251-269.

BARON, D. P., AND D. BESANKO, "Regulation, Asymmetric Information, and Auditing," Rand Journal of Economics 15 (1984), 447470.

—, AND R. B. MYERSON, "Regulating a Monopolist with Unknown Costs,” Econometrica 50 (1982), 91 1-930.

CAVE, J., AND S. W. SALANT, "Cartels That Vote: Agricultural Marketing Boards and Induced Voting Behavior," in Bailey, ea., Public Regulation (Cambridge: MIT Press, 1987), 255-283.

CLARKE, R. N., "Collusion and the Incentives for Information Sharing," Bell Journal of Economics 14 (1983), 383-394.

CRAMTON, P., R. GIBBONS, AND P. KLEMPERER, “Dissolving a Partnership Efficiently,” Econometrica 55 (1987), 615-632.

- AND T. R. PALFREY, "Participation Constraints in Mechanism Design: Learning from Disagreement," working paper, Yale School of Management and California Institute of Technology, 1989.

CREMER, J., AND R. McLEAN, "Full Extraction of the Surplus in Bayesian and Dominant Strategy Auctions," Econometrica 56 (1988), $1247-1258$.

FUDENBERG, D., AND E. MASKIN, "The Folk Theorem in Two-Person Repeated Games with Discounting and Incomplete Information," Econometrica 54 (1986), 533-554.

GAL-OR, E., "Information Sharing in Oligopoly," Econometrica 53 (1985), 329-343.

— , "Information Transmission: Cournot and Bertrand Equilibria," Review of Economic Studies 53 (1986), 85-92.

GREEN, E. J., AND R. H. PORTER, “Noncooperative Collusion Under Imperfect Price Information,” Econometrica 52 (1984), 87-100.

HALLAGAN, W. S., "Contracting Problems and the Adoption of Regulatory Cartels," Economic Inquiry 23 (1985), 37-57.

HENDRICKS, K., AND R. H. PORTER, “An Empirical Study of an Auction with Asymmetric Information, American Economic Review 78 (1988), 865-883.

KIHLSTROM, R. E., AND X. VIVES, “Collusion by Asymmetrically Informed Firms,” working paper, University of Pennsylvania, 1989.

LAFFONT, J., AND J. TIROLE, "Using Cost Observation to Regulate Firms,” Journal of Political Economy 94 (1986), 614-641.

LOEB, M., AND W. A. MAGAT, “A Decentralized Method for Utility Regulation,” Journal of l aw and Economics 22 (1979), 399-04.

MADRIGAL, V., "Collusion Under Asymmetric Information,” working paper, University of Chicago, Graduate School of Business, 1988.

MASKIN E., AND J. RILEY, “Optimal Auctions with Risk Averse Buyers,” Econometrica 52 (1984), 1473-1518.

McAFEE, R. P., AND J. McMILLAN, “Bidding Rings,” working paper, University of Western Ontario, 1987.

—, AND P. J. RENY, “Correlated Information and Mechanism Design,” working paper, University of Western Ontario, 1988.

MYERSON, R. B., "Optimal Auction Design," Mathematics of Operations Research 6 (1981), 58-73.

, AND M. A. SATTERTHWAITE, "Efficient Mechanisms for Bilateral Trading,” Journal of Economic Theory 28 (1983), $265-281$.

PALFREY, T. R., "Uncertainty Resolution, Private Information Aggregation and the Cournot Competitive Limit," Review of Economic Studies 52 (1985), 69-83.

PORTER, R. H., "Optimal Cartel Trigger Price Strategies,” Journal of Economic Theory 29 (1983), 313-338.

RIORDAN, M. H., AND D. E. M. SAPPINGTON, “Awarding Monopoly Franchises,” American Economic Review 77 (1987), $375-387$. 
ROBERTS, K., “Self-Agreed Cartel Rules,” working paper, IMSSS, Stanford University, 1983.

, "Cartel Behaviour and Adverse Selection," Journal of Industrial Economics (1985), 3345.

SHAPIRO, C., "Exchange of Cost Information in Oligopoly," Review of Economic Studies 53 (1986), 433-446.

SHEPARD, L., "Cartelization of the California-Arizona Orange Industry, 1934-1981," Journal of Law and Economics 29 (1986), 83-123.

VIVES, X., "Duopoly Information Equilibrium: Cournot and Bertrand," Journal of Economic Theory 34 (1984), 71-94. 